\title{
Endogenous Cytokine Responses and Unexpected Survival in a Phase I Trial Using Anti-CD3 x Anti-HER2 Bispecific Antibody Armed Activated T Cells (HER2 BATs) for Treatment of Women with Stage III Breast Cancer
}

Archana Thakur ( $\nabla$ at2fx@virginia.edu )

University of Virginia https://orcid.org/0000-0003-3876-9555

Lawrence G Lum

University of Virginia

Gerald A Colvin

Roger Williams Medical Center

Patrick Dillon Patrick Dillon

University of Virginia

Ritesh Rathore Ritesh Rathore

Roger Williams Medical Center

\section{Research article}

Keywords: Bispecific antibody, activated T cells, Immunotherapy, adjuvant therapy of breast cancer, HER2 BATs

Posted Date: July 4th, 2019

DOI: https://doi.org/10.21203/rs.2.10980/v1

License: @ (i) This work is licensed under a Creative Commons Attribution 4.0 International License. Read Full License 


\section{Abstract}

BACKGROUND: Advanced stage breast cancer has unacceptably high recurrence rates. In this study, we report a phase I immunotherapy (IT) trial in women with high risk (>3 positive nodes) breast cancer that seeks to determine safety and maximum tolerated dose (MTD) of anti-CD3 $x$ anti-HER2 bispecific antibody (HER2Bi) armed activated T cells (HER2 BATs), with the secondary objective of determining whether IT induces endogenous cytokine changes. METHODS: The phase I trial consisted of 8 twice weekly infusions of HER2 BATs given in a $3+3$ dose escalation with groups of 3 patients receiving 5,10 , or $20 \times 109$ HER2 BATs per infusion. HER2 BATs were given in combination with daily low dose interleukin 2 (IL-2) and twice weekly low dose granulocytemacrophage colony-stimulating factor (GM-CSF) to determine safety, the maximum tolerated dose (MTD), technical feasibility, immune cytokine responses, time to progression (TTP), and overall survival (OS). RESULTS: Nine women with stage III breast cancer were enrolled at a single institution. There were no dose limiting toxicities (DLTs) and the MTD was not defined. It was technically feasible to grow $176 \times 109$ ATC from a single apheresis. Five of 9 women are alive with no evidence of disease with an undefined median OS. Infusions of HER2 BATs induced increases in serum Th1 cytokines, and some of these changes persisted for weeks to months after IT. CONCLUSIONS: Targeting HER2 positive and negative tumors with BATs infusions was safe, induced Th1 cytokines and IL-12 responses in the serum providing evidence for inducing changes in the endogenous immune system of the patients. The prolonged survival that is undefined with a median follow up of 12.7 years suggests that targeting tumors in the adjuvant setting with HER2 BATs may help eliminate microscopic residual disease after surgery, irradiation, and chemotherapy. TRIAL REGISTRATION: The protocol entitled "Combination Chemotherapy Plus Biological Therapy in Treating Patients with Stage II or Stage III Breast Cancer" as a phase I/II was registered January 27, 2003, with NCT00022230 under clinicaltrials.gov.

\section{Background}

Breast cancer accounts for 1 in 3 cancers in women and is the second leading cause of cancer death among women in the United States. About $10 \%$ of women with localized breast cancer develop metastatic breast cancer (MBC) in 5 years. Most metastatic breast cancer (MBC) patients achieve objective responses to chemotherapy or hormonal therapies; progression is inevitable and long-term survival is dismal.[ 1-3] The critical strategy for improving survival is to prevent the development of MBC by providing effective anti-breast cancer activity in the high risk adjuvant setting. Cancer spread to regional lymph nodes is a leading predictor of eventual MBC development. Survival rates are inversely related to the number of nodes in patients with localized breast cancer.[2] Despite optimal adjuvant chemotherapy, patients with extensive nodal involvement at diagnosis have poor outcomes.[1] Non-toxic strategies are needed to decrease the number of women who develop MBC.

HER2 is overexpressed in breast, ovarian, lung, gastric, oral, and prostate cancers, and it is an ideal target given low levels of expression on normal tissues. HER2 targeted agents include trastuzumab, pertuzumab, $[4,5]$ and TDM1 [ 6] for treatment of HER2expressing MBC.

Our preclinical studies show that anti-CD3 $x$ anti-HER2 bispecific antibody (HER2Bi) armed activated $T$ cells (BATs) exhibit specific cytotoxicity against 0-3+ HER2-expressing breast cancer cell lines.[ 7] Arming ATC with bispecific antibody converts every ATC into anti-HER2 targeted cytotoxic T lymphocyte that can target and kill low or even nil HER2 expressing cell lines.[ 7-9] In phase I trials in women with MBC and in men with hormone refractory prostate cancer, these HER2 BATs infusions were safe, induced robust endogenous immune responses, and suggested a survival benefit in median overall survival (OS) in breast cancer, as well as decreases in prostate specific antigen in men with hormone refractory prostate cancer.[10,11]

Treatment combinations of doxorubicin (A), paclitaxel (T), and cyclophosphamide (C) are considered standard adjuvant chemotherapy for patients after resection of breast cancer involving $>3$ axillary nodes. When this study was conducted between 2001 and 2006, a number of studies in high risk pts with >3LN's had 5 year disease free survival ranging from 60 to $80 \%$. [12-15]

In this study, long-term follow-up is presented for women with stage III breast cancer who received standard of care adjuvant therapy followed by immunotherapy with HER2 BATs infusions administered with low dose interleukin 2 (IL-2) and granulocyte-macrophage colony-stimulating factor (GM-CSF). We designed the trial to ask three questions: 1) Are HER2 BATs safe and technically feasible? 2) Do HER2 BATs induce changes in serum cytokine patterns before, during, and after infusions? 3) Does this combination of immunotherapy improve time to progression (TTP) or overall survival (OS)? Because this was a phase I pilot study with limited funds, the study was constrained to 9 patients. The impetus to submitting this report was driven by unexpected long-term clinical 
results. Infusions of BATs were safe, feasible, induced marked changes in cytokine levels, and may have provided clinical anti-tumor activity in this high-risk adjuvant population of patients.

\section{Methods}

Clinical Protocol. The protocol entitled "Combination Chemotherapy Plus Biological Therapy in Treating Patients with Stage II or Stage III Breast Cancer" was initiated as a phase I/II and registered January 27, 2003, with NCT00022230. Patients were enrolled (RWH 03-356-46) at Roger Williams Medical Center in Providence (RWMC), RI, between April 30, 2002 and 2006, with follow-up until April of 2019. The protocol was reviewed and approved by protocol review committee, institutional Human Investigational Committees at RWMC, and the Food and Drug Administration. The trial was monitored by RWMC data safety monitoring committee. All patients signed informed-consent prior to enrollment.

HER2Bi Production. The HER2 BATS were produced by chemically heteroconjugating trastuzumab (Herceptin®, Genentech, CA) to muromonab-CD3 (OKT3, Miltenyi Biotec, CA) under cGMP conditions.[ 7] The product was released after bacterial and fungal cultures were negative for 7 days, testing for mycoplasma was negative, and the endotoxin levels were determined. Phenotyping and functional testing of the product was documented.

Phase I Clinical Trial Design. The primary endpoint of this standard $3+3$ dose escalation trial was to determine the safety and maximum tolerated dose (MTD) of HER2 BATs with dose levels of 5, 10, and 20 billion HER2 BATs/infusion. Patients received 2 infusions/week for 4 weeks, for total doses of 40,80 , and $160 \times 10^{9}$ BATs. BATs were given in combination with subcutaneous injections of IL-2 (300,000 IU/m²/day) and GM-CSF (250 $\mathrm{\mu g} / \mathrm{m}^{2} /$ twice weekly) beginning 3 days before the $1^{\text {st }}$ infusion and ending 1 week after the last BATs infusion. Figure 1A shows the treatment schema. Tumor evaluations were performed per standard of care followed by the referring physicians. All patients were followed for OS.

Eligibility Criteria. Patients with the following high-risk characteristics were eligible: histologically documented infiltrating ductal adenocarcinoma of the breast; node positive (stages T1-3); node negative (T2 stage, T1c stage \& ER/PR negative, T1c stage); tumors with $0-3+\mathrm{HER} 2 /$ neu on immunohistochemistry $(\mathrm{IHC})$ confirmed by pathology; women $>18$ years of age; Karnofsky score of $>70 \%$ or ECOG 0-2; non-pregnant; life expectancy of >3 months; no previous or concurrent malignancy; and curatively treated in situ squamous cell carcinoma of the cervix or basal cell carcinoma of the skin allowed. Patients were ineligible if there was: a recent myocardial infarction (within one year); history of a past myocardial infarction ( $>1$ year ago) associated with current coronary symptoms requiring medications and/or evidence of depressed left ventricular function (LVEF $<50 \%$ by MUGA); a current history of angina/coronary symptoms requiring medications and/or evidence of depressed left ventricular function (LVEF $<50 \%$ by MUGA); evidence of congestive heart failure requiring medical management; serious medical or psychiatric illness which prevents informed consent or intensive treatment. Details of patient characteristics are presented in Table 1.

Leukapheresis, T cell Expansion, and Production of BATs. ATC were produced from the leukapheresis product as described.[ 10] After ex vivo expansion, ATC were harvested, armed, and cryopreserved.[10] Aliquots from cryopreserved BATs were submitted for bacteria and fungus, endotoxin, mycoplasma, phenotype, and cytotoxicity testing. BATs were released for infusions only after passing all release criteria as previously described.[10]

Dose Modification and Toxicity Scoring (NCl Toxicity Criteria, v2, June 1, 1999). Patients were accrued to each dose level based on the dose-escalation schema. If 1 in the first 3 patients or 2 in the first 6 patients experienced persistent grade 3 non-hematological toxicity or grade 4 toxicity, the dose would not be escalated. Patients with grade 4 non-hematologic toxicity were removed from protocol. Patients who experienced a $10 \%$ decrease in the ejection fraction would be removed from protocol and treatment stopped. Treatment was held for grade 3 toxicity until toxicity decreased to grade $0-1$. If grade 3 toxicity recurred, the subsequent dose of BATs was washed to eliminate dimethysulfoxide. If toxicity persisted, the next dose was reduced by $50 \%$. If the toxicities persisted at the reduced dose of BATs, IL-2 would be stopped but the BATs infusions continued. If grade 3 toxicity occurred again, the BATs infusions would be stopped. Toxicities were assessed for 7 days after each infusion. Toxicities were followed until they resolved.

Immune Function Assays. Cytokine patterns were obtained by multiplex cytokine array using the Bio-Plex system (Bio-Rad Lab., Hercules, CA). 
Statistics. The primary endpoint of the study was to determine safety and MTD of BATs. The secondary endpoint was to assess OS, which was measured from the date of enrollment. Descriptive statistical analyses were used to analyze immune responses using GraphPad Prism (GraphPad, Version 6.0).

\section{Results}

Patient Characteristics. Table 1 summarizes the clinical characteristics, prior therapy, the planned and infused doses of HER2 BATs, and OS for 9 women with high risk breast cancer. Median age was 49 years (range: 38-69 years). All patients received adjuvant chemotherapy and surgery with or without irradiation. Table 2 summarizes the patient characteristics. Five of 9 women were less than 50 years of age. Eight women had >10 nodes positive for tumor, and 1 woman had 2 nodes positive for tumor. Eight women had ER/PR positive tumors, and 1 had an ER/PR negative tumor. Two women had tumors that were HER2 $3+$, and 2 women had tumors that were HER2 1-2+. Five women had HER2 negative tumors. No one received trastuzumab prior to therapy.

Phenotype and Cytotoxicity of BATs. The proportion of CD3, CD4, and CD8 T cells in the apheresis product and the harvest product in shown in Figure 3. Table 3 shows the data for each patient. The mean percent ( \pm SD) viability was $91.4 \pm 5.2 \%$. The mean proportion $(95 \% \mathrm{Cl})$ of CD3, CD4, and CD8 cells were $92 \%$ (78.4 - 95), 35\% (19-70), and 52\% (22- 88), respectively.

Phase I Evaluation of Toxicities. The most frequent side effect (SE) was grade 3 chills. Grade 1 and 2 fever and malaise emerged as the second most common SE. Table 4 shows the frequency of side effects ( $\mathrm{NCl}$ Immunotherapy Protocol Toxicity Criteria, v2). By episode per infusion, the incidence of chills and fever were $66.6 \%$ each. All patients with grade 3 chills responded to meperidine. There were no hospitalizations. There were no DLTs attributed to HER2 BATs.

Phase I Evaluation of MTD. The highest dose level completed was $20 \times 10^{9}$ BATs per infusion ( $160 \times 10^{9}$ total dose of BATs); thus, $160 \times 10^{9}$ given in 8 divided doses is a technically feasible dose. Table 1 shows the planned doses and actual doses for 9 patients.

Overall Survival. Figure 1B shows the K-M curve for all 9 patients. The median OS for 9 patients remains undetermined (14-164 months) with a median follow-up of 12.7 years.

Serum cytokines. Serum was available for 5 of 9 patients to be tested (Figure 2) for serum cytokine levels pre-IT baseline serum (BASE), after each BATs infusion, and 1 week and 1 month post completion of all infusions to determine whether IT induced changes in serum cytokine profiles ( $n=5)$. One patient (FG60031) did not have detectable levels of any of the cytokines tested. Table 5 shows the detailed data shown in Figure 2 on the cytokine levels in tabular form for each patient at the designated time points. The peak levels for each patient and levels that remained elevated at a week or beyond are bolded to indicate persistent levels.

IL-2 levels in FG60114, FG60119, FG60200, and FG60135 peaked at $592 \mathrm{pg} / \mathrm{ml}$ after the 5 th infusion, $47 \mathrm{pg} / \mathrm{ml}$ after the 4th infusion, $3586 \mathrm{pg} / \mathrm{ml}$ after the 4th infusion, and $586 \mathrm{pg} / \mathrm{ml}$ after the 6 th infusion, respectively. Four of 5 patients (FG60114, FG60119, FG60200, and FG60135) had detectable IL-2 levels of 208, 9, 38, and 73 pg/ml, respectively. Three of 5 had persistent levels of IL-2 at 1 month. One patient (FG60114) had a level of $260 \mathrm{pg} / \mathrm{ml}$ at 2 months after immunotherapy. The IL-2 levels for FG60114 could not be attained by injections of low doses of IL-2. The source of the IL-2 levels after 1 week had to be produced by endogenous T cells.

The IFN-y serum levels were variable. Three of 5 patients had elevated IFN-y levels prior to the 1 st infusion, and IFN-y levels peaked at $121 \mathrm{pg} / \mathrm{ml}$ after 6 infusions in FG60114, and at $181 \mathrm{pg} / \mathrm{ml}$ after 4 infusions in FG60200. The high baseline level of $320 \mathrm{pg} / \mathrm{ml}$ for patient FG60114 may be due to a high endogenous level in the patient, or IFN- $₫$ secretion triggered by infusions of low dose IL-2 and GM-CSF. Patient FG60114 had levels that persisted for 2 months.

GM-CSF in FG60114, FG60200, and FG60135 peaked at $83 \mathrm{pg} / \mathrm{ml}$ after the 6th infusion, $281 \mathrm{pg} / \mathrm{ml}$ after the 4th infusion, and 45 $\mathrm{pg} / \mathrm{ml}$ after the 5th infusion, respectively. A GM-CSF level of $21 \mathrm{pg} / \mathrm{ml}$ persisted 2 months after IT. The rise and persistence of serum GM-CSF was easily detectable and above levels that could be attained by biweekly injections of low dose GM-CSF.

TNF-[Din FG60114, FG60119, FG60200, and FG60135 peaked at $35 \mathrm{pg} / \mathrm{ml}$ after the 6th infusion, $10 \mathrm{pg} / \mathrm{ml}$ after the 7th infusion, at $52 \mathrm{pg} / \mathrm{ml}$ after the 4th infusion, and at $22 \mathrm{pg} / \mathrm{ml}$ after the 4th infusion, respectively. TNF-a was detectable 1 week after IT in 4 of 5 patients, with persistence of TNF-a in FG60114 at 2 months after IT. 
IL-12 levels rose in 3 (FG60114, FG60200, and FG60135) out of 5 patients to $126 \mathrm{pg} / \mathrm{ml}$ after 6 infusions, $522 \mathrm{pg} / \mathrm{ml} \mathrm{after} 4$ infusions, and $88 \mathrm{pg} / \mathrm{ml}$ after 6 infusions, respectively. These data show the IL-12 produced by monocyte activation was induced by HER2 BATs since T cells do not produce IL-12. IL-12 synthesis by monocytes is a critical step in antigen-presentation and activation of immune cells in the tumor microenvironment leading to the immunization of the endogenous immune system.

Serum IL-13 levels in 4 of 5 patients peaked infusions 5 and 6, respectively. (Figure 2, Table 5). IL-13 persisted beyond 1 week after the last infusion in 3 patients.

The levels of IL-4 were below detectable levels for all patients (data not shown), and levels of IL-5 were near background (0-5 pg/ml) at all time points, except for a level of $11 \mathrm{pg} / \mathrm{ml}$ that was detected in the serum of FG60114 prior to the $1^{\text {st }}$ infusion.

IL-10 levels were detected in 4 of 5 patients. IL-10 levels in FG60114, FG60119, FG60200, and FG60135 peaked at 229 pg/ml after 5 infusions, $31 \mathrm{pg} / \mathrm{ml}$ after 3 infusions, $805 \mathrm{pg} / \mathrm{ml}$ after 4 infusions, and $171 \mathrm{pg} / \mathrm{ml}$ after 7 infusions, respectively. Three of 5 patients had IL-10 levels that were detectable 1 week after IT, and FG60114 had levels of 89 and $49 \mathrm{pg} / \mathrm{ml}$ after 1 and 2 months after IT, respectively.

The lower right panel of Figure 2 shows the mean $\mathrm{Th}_{1} / \mathrm{Th}_{2}$ ratio $=$ [IL-2 + IFN-] / [IL-4 + IL-10] at the pre-infusion, mid-infusion, and post-IT time points. The nil levels of IL-4 were used to calculate the $T h_{1} / T h_{2}$ ratios. The $T h_{1} / T h_{2}$ ratio was elevated above normal after infusion 4 and persisted more than a month after immunotherapy was finished.

Correlates between cytokine patterns and survival. Since the number of patients in the study cohort was small, it is difficult to draw any conclusions from the immune correlates; however, there are several key observations. First, infusions of HER2 BATs induced endogenous immune cells to produce easily detectable cytokine levels of IFN-y, IL-12, TNF-a, IL-10, IL-13, IL-5, and $s \mathrm{ft}_{\mathrm{ft}} \mathrm{Th}_{\mathrm{T}} \mathrm{Th}_{1} / \mathrm{Th}_{2}$ after 4 infusions to a Th 1 pattern. Second, the increased levels of IL-2 and GM-CSF could not have been a result of the injections of low dose IL-2 and GM-CSF. The most notable observations are that IL-2 and GM-CSF levels did not develop until after nearly 2 weeks after the therapy began, and the levels of IL-2 and GM-CSF persisted beyond one week in several patients. Such levels would represent synthesis by endogenous immune cells beyond any time that injected IL-2 and GM-CSF could persist.

\section{Discussion}

The results from this phase I pilot trial of HER2 BAT infusions in women with stage III high risk breast cancer in the adjuvant setting are clinically encouraging. Multiple infusions of BATs in combination with IL-2 and GM-CSFwere safe and technically feasible. The doses of HER2 BATs required for cell processing and arming with HER2Bi were easily achievable. The long-term follow-up with a median OS that is not defined with a median follow-up of 12.7 years shows the potential clinical benefit for prolonging time to progression and OS in this small group of 9 patients. The median OS is undetermined for 9 patients. IT-induced endogenous cytokine responses persisted 1-2 months post completion of infusions, similar to what was previously reported in the metastatic breast cancer trial.[ 10]

When interpreting these results in the context of contemporaneous therapies in patients who received adjuvant treatment with anthracyclines and taxanes for breast cancer with $>10$ lymph nodes, it is notable that median 10 -year OS ranged from $29 \%$ to $42 \%$.[ 15] The median OS in this group has not been reached, with the proportion of patients surviving $14+$ years $>55 \%$. In this phase I study, most patients had >10 nodes. The major side effects were chills, fever, headache, fatigue, and hypotension. Mild cytokine "flurries" were observed, but there were no life-threatening cytokine "storms," and no patients were admitted to the hospital. Increases in serum $\mathrm{Th}_{1}$ cytokine levels leading to high $\mathrm{Th}_{1} / \mathrm{Th}_{2}$ ratios and increases in IL-12 that developed mid IT and persisted for weeks after IT show that the immunologic milieu and tumor microenvironment were shifted towards an anti-tumor environment.

Despite the encouraging safety and immunologic findings, an expansion cohort was not pursued due to lack for funding for such a trial. However, in a phase I metastatic breast cancer trial, we showed that the infused HER2 BATs were able to induce endogenous immune responses leading to in situ immunization of the patient. The immunization of the patients with HER2 BATs induced the development of long-term anti-tumor effector cells that may be responsible for increasing survival in a small cohort of patients. Fifty-nine percent of the patients had stable disease at 14.5 weeks, and the median OS for the entire group was 36.2 months. Multiple infusions of HER2 BATs in combination with low dose IL-2 and GM-CSF induced endogenous cytotoxic T cells that would

Page 5/18 
kill breast cancer lines, as well as induce the development of humoral and innate immunity.[10] Our follow-up in a proof of principle study confirmed that tumor specific effector memory $T$ cells and B cells producing antibodies directed at breast cancer antigens can be transferred by expanded immune activated T cells (ATC) and immune cells in the stem cell product given after high dose chemotherapy and autologous stem cell transplant (SCT).[ 16] High dose chemotherapy created "immune space" for ATC to expand and accelerate reconstitution of cellular and humoral immunity against breast cancer antigens within 4 weeks after SCT. Low dose IL-2 and GM-CSF were given to a few patients after SCT, but there was no obvious difference in the immune responses. CTL responses and specific IgG to various tumor peptides were detected to different epitopes of HER2, EGFR, carcinoembryonic antigen. These antibody data directed at multiple epitopes of HER2 and the non-targeted antigens EGFR and CEA showed that there was not only epitope spreading, but also antigen spreading after targeting HER2 antigen on the breast cancer. The specific CTL responses persisted up to 3 years.

\section{Conclusions}

These results provide the rationale for the design of phase II clinical trials using HER2 BATs in breast cancer and other solid tumors in the adjuvant setting where there is minimal residual disease. Because this was a phase I study with limited funds, there were only 9 patients. Because the sample size was small, there was originally no intent on submitting the data; however, the delay in reporting led to the unexpected encouraging clinical long-term survival and no evidence of disease on follow-up. These results provide significant rationale for designing approaches that use different form targeted T cells to clean up residual microscopic disease in the adjuvant or neoadjuvant setting.

\section{Abbreviations}

OKT3: Muromonab-CD3 antibody

HER2: Epidermal growth factor receptor-2

EGFR: Epidermal growth factor receptor-2

\section{CEA: Carcinoembryonic antigen}

HER2Bi: Anti-CD3 x Anti-HER2 Bispecific antibody

HER2 BATs: Anti-CD3 x Anti-HER2 Bispecific antibody armed Activated T cells

ATC: Activated T cells

CTL: Cytotoxic T Lymphocytes

\section{GM-CSF: Granulocyte-Macrophage Colony Stimulating Factor}

IFN-ץ: Interferon gamma

TNF-a: Tumor Necrosis Factor-alpha

IL-2: Interleukin-2

IL-12: Interleukin-12

IL-10: Interleukin-10

IL-13: Interleukin-13

IL-5: Interleukin-5 
SCT: Stem Cell Transplant

MTD: Maximum Tolerated Dose

DLT: Dose Limiting Toxicities

TTP: Time to Progression

OS: Overall Survival

\section{Declarations}

\section{Ethics approval and consent to participate:}

The protocol was reviewed and approved by protocol review committee, institutional Human Investigational Committees at RWMC, and the Food and Drug Administration. The trial was monitored by RWMC data safety monitoring committee. All patients signed informed-consent prior to enrollment.

\section{Consent for publication:}

All patient were informed that the clinical data could potentially be published.

\section{Availability of data and material:}

The de-identified research and clinical data are available to the public.

\section{Competing Interests:}

L.G.L. is the co-founder of Transtarget, Inc., the exclusive licensee of bispecific antibody armed T cells (BATs). He also sits on the Scientific Advisory Board for Rapa Therapeutics. A.T. is a co-founder of Nova Immune Platform, Inc. P.D. participates in trials by Merck, Pfizer, Tesaro, Newlink Genetics, Seattle Genetics, Novartis, and Eli Lilly. R.R. has no conflicts of interest.

\section{Funding:}

The funds from NCl R01 CA 092344, R01 CA 140314, and startup funds from Roger Williams Medical Center, Karmanos Cancer Institute, and University of Virginia Cancer Center supported this clinical study.

\section{Authors' Contributions:}

L.G.L, A.T. and P.D. wrote the manuscript. L.G.L. and R.R. were involved in the design, writing, and clinical management of the protocol and cell infusions. L.G.L. sponsored the IND and supervised the production of the cGMP product, immune evaluation assays, and data management and collection. A.T. assisted in the data analysis. All authors have read and approved the manuscript.

\section{Acknowledgements}

Special thanks to the nurses and nurse clinical coordinators: Wendy Young, Annette Olson, Lori Hall, Janet Mclntyre, and Kristie Fields who provided scheduling, informational, emotional and follow up support to the women who participated in this clinical trial. The immunotherapy team acknowledges the special efforts of members of the Immunotherapy Program at Roger Williams Hospital and the BMT/Immunotherapy Program who have provided support and infrastructure for the compassionate care of women with breast cancer. We also thank Taylor Matousek for her editorial assistance. 


\section{References}

References

1. Nabholtz JM, Senn HJ, Bezwoda WR, Melnychuk D, Deschenes L, Douma J, Vandenberg TA, Rapoport B, Rosso R, Trillet-Lenoir V et al: Prospective randomized trial of docetaxel versus mitomycin plus vinblastine in patients with metastatic breast cancer progressing despite previous anthracycline-containing chemotherapy. 304 Study Group. JClinOnco/ 1999, 17(5):1413-1424.

2. Muss HB, Case LD, Richards F, White DR, Cooper MR, Cruz JM, Powell BL, Spurr CL, Capizzi RL: Interrupted versus continuous chemotherapy in patients with metastatic breast cancer. The Piedmont Oncology Association. NEnglJMed 1991, 325(19):13421348.

3. Harris J, Morrow M, Bonadonna G: Cancer. Principles and Practice of Oncology, 4 edn. Philadelphia: Lippincott; 1993.

4. von Minckwitz G, Procter M, de Azambuja E, Zardavas D, Benyunes M, Viale G, Suter T, Arahmani A, Rouchet N, Clark E et al: Adjuvant Pertuzumab and Trastuzumab in Early HER2-Positive Breast Cancer. New England Journal of Medicine 2017, 377(2):122131.

5. Swain SM, Baselga J, Kim S-B, Ro J, Semiglazov V, Campone M, Ciruelos E, Ferrero J-M, Schneeweiss A, Heeson S et al: Pertuzumab, Trastuzumab, and Docetaxel in HER2-Positive Metastatic Breast Cancer. New England Journal of Medicine 2015, 372(8):724-734

6. Verma S, Miles D, Gianni L, Krop IE, Welslau M, Baselga J, Pegram M, Oh DY, Dieras V, Guardino E et al: Trastuzumab emtansine for HER2-positive advanced breast cancer. New England Journal of Medicine 2012, 367(19):1783-1791.

7. Sen M, Wankowski DM, Garlie NK, Siebenlist RE, Van Epps D, LeFever AV, Lum LG: Use of anti-CD3 x anti-HER2/neu bispecific antibody for redirecting cytotoxicity of activated T cells toward HER2/neu+ tumors. J Hematother Stem Cell Res 2001, 10(2):247260.

8. Grabert RC, Cousens LP, Smith JA, Olson S, Gall J, Young WB, Davol PA, Lum LG: Human T cells armed with Her2/neu bispecific antibodies divide, are cytotoxic, and secrete cytokines with repeated stimulation. Clin Cancer Res 2006, 12(2):569-576.

9. Davol PA, Smith JA, Kouttab N, Elfenbein GJ, Lum LG: Anti-CD3 x anti-HER2 bispecific antibody effectively redirects armed T cells to inhibit tumor development and growth in hormone-refractory prostate cancer-bearing severe combined immunodeficient beige mice. Clin Prostate Cancer 2004, 3(2):112-121.

10. Lum LG, Thakur A, Al-Kadhimi Z, Colvin GA, Cummings FJ, Legare RD, Dizon DS, Kouttab N, Maizel A, Colaiace W et al: Targeted T cell Therapy in Stage IV Breast Cancer: A Phase I Clinical Trial. Clinical Cancer Research 2015.

11. Vaishampayan UN, Thakur A, Rathore R, Kouttab N, Lum LG: Phase I Study of Anti-CD3 x Anti-Her2 Bispecific Antibody in Metastatic Castrate Resistance Prostate Cancer patients. Prostate Cancer 2015.

12. Fountzilas G, Skarlos D, Dafni U, Gogas H, Briasoulis E, Pectasides D, Papadimitriou C, Markopoulos C, Polychronis A, Kalofonos HP et al: Postoperative dose-dense sequential chemotherapy with epirubicin, followed by CMF with or without paclitaxel, in patients with high-risk operable breast cancer: a randomized phase III study conducted by the Hellenic Cooperative Oncology Group. Annals of Oncology 2005, 16(11):1762-1771.

13. Martin M, Rodriguez-Lescure A, Ruiz A, Alba E, Calvo L, Ruiz-Borrego M, Munarriz B, Rodriguez CA, Crespo C, de Alava E et al: Randomized phase 3 trial of fluorouracil, epirubicin, and cyclophosphamide alone or followed by Paclitaxel for early breast cancer. $J$ Natl Cancer Inst 2008, 100(11):805-814.

14. Roché H, Fumoleau P, Spielmann M, Canon J-L, Delozier T, Serin D, Symann M, Kerbrat P, Soulié P, Eichler F et al: Sequential Adjuvant Epirubicin-Based and Docetaxel Chemotherapy for Node-Positive Breast Cancer Patients: The FNCLCC PACS 01 Trial. Journal of Clinical Oncology 2006, 24(36):5664-5671. 
15. Wishart GC, Azzato EM, Greenberg DC, Rashbass J, Kearins O, Lawrence G, Caldas C, Pharoah PD: PREDICT: a new UK prognostic model that predicts survival following surgery for invasive breast cancer. Breast Cancer Research 2010, $12(1): R 1$.

16. Thakur A, Rathore R, Kondadasula SV, Uberti JP, Ratanatharathorn V, Lum LG: Immune T cells can transfer and boost anti-breast cancer immunity. Oncoimmunology 2018, 7(12):e1500672.

\section{Tables}

Table 1. Age, Receptors, Prior Treatment, Number of Nodes, BATs doses, Specific Cytotoxicity, and Survival 


\begin{tabular}{|c|c|c|c|c|c|c|c|c|c|c|c|c|}
\hline & Pt \# & Age & ER & PR & HER2 & $\begin{array}{l}\text { Prior } \\
\text { Treatment }^{\mathrm{a}}\end{array}$ & $\begin{array}{l}\text { Stage/\# } \\
\text { Positive } \\
\text { Nodes }\end{array}$ & $\begin{array}{l}\text { Planned } \\
\text { BATs } \\
\text { Dose } \\
\left(10^{9}\right)\end{array}$ & $\begin{array}{l}\text { BATs } \\
\text { Dose } \\
\left(10^{9}\right)\end{array}$ & $\begin{array}{l}\text { Product } \\
\text { Cytotoxicity }\end{array}$ & $\begin{array}{l}\text { Survival } \\
\text { (years) }\end{array}$ & $\begin{array}{l}\text { Alive } \\
\text { (A) } \\
\text { or } \\
\text { Dead } \\
\text { (D) }\end{array}$ \\
\hline 1 & 00482 & 67 & + & + & $2+$ & $\begin{array}{l}\text { DD, Chem, } \\
\text { Mast, Rad, } \\
\text { H }\end{array}$ & S3/NA & 20 & 21.6 & 67.3 & 1.2 & D \\
\hline 2 & $60031 / 51^{c}$ & 62 & + & + & - & $\begin{array}{l}\text { Lump, } \\
\text { Chemo, } \\
\text { Rad, H }\end{array}$ & $\mathrm{S} 3 / 10$ & 40 & 42.75 & 39.5 & 16.6 & A \\
\hline 3 & 60119 & 44 & + & - & - & $\begin{array}{l}\text { Chemo, } \\
\text { Rad, Mast, } \\
\text { H }\end{array}$ & $\mathrm{S} 3 / 10$ & 40 & 37.6 & 44.1 & 6.4 & D \\
\hline 4 & 60114 & 38 & - & - & $3+$ & $\begin{array}{l}\text { Chemo, } \\
\text { Mast, Rad }\end{array}$ & S3/NA & 40 & 42.4 & 58.7 & 1.8 & D \\
\hline 5 & 60200 & 59 & + & + & - & $\begin{array}{l}\text { Lump, } \\
\text { Mast, 5FU, } \\
\text { epirubicin, } \\
\text { Cytoxan \& } \\
3 \text { taxotere, } \\
\text { Rad }\end{array}$ & $\mathrm{S} 3 / 13$ & 80 & 80 & 73.2 & 3.7 & $\mathrm{D}$ \\
\hline 6 & 60135 & 49 & + & + & $1+$ & $\begin{array}{l}\text { Lump, } \\
\text { Chemo, } \\
\text { Rad, H }\end{array}$ & $\mathrm{S} 3 / 10$ & 80 & 70.35 & 36.8 & 15.1 & A \\
\hline 7 & 91787 & 38 & + & + & $3+$ & $\begin{array}{l}\text { R simple } \\
\text { Mast, } \\
\text { Chem, } \mathrm{H}\end{array}$ & & 80 & 96 & 67.3 & 14.6 & \\
\hline & & & & & & & $\mathrm{S} 3 / 18$ & & & & & A \\
\hline 8 & $91801^{d}$ & 69 & + & + & - & $\begin{array}{l}\text { L partial } \\
\text { Mast, } \\
\text { Chem, Rad, } \\
\text { H }\end{array}$ & $\mathrm{S} 3 / 16$ & 160 & 176.75 & 69.1 & 14.0 & A \\
\hline 9 & 01717 & 44 & + & + & - & $\begin{array}{l}\text { Lump, } \\
\text { Chemo, } \\
\text { Total } \\
\text { Mast, Rad, } \\
\text { H }\end{array}$ & $\mathrm{S} 2 / 2$ & 160 & 160 & 26.7 & 12.6 & A \\
\hline
\end{tabular}

A: Chemo including dose dense or standard dosing of AC-T (Doxorubicin and cyclophosphamide, followed by Paclitaxel), AC (Adriamycin and cyclophosphamide), ATC (Adriamycin, Cytoxan \& Taxol); Rad: All modalities of radiation; H: all types of hormonal;: b: ${ }^{51} \mathrm{Cr}$ Specific Cytotoxicity at effector: target ratio (E:T) of 25:1 directed at breast cancer cell line. C: Patient's T cells were expanded 
twice; S3: Stage III; NA: number not available; and d: This patient developed a Right breast cancer in 2009 and was treated with Radiation therapy

Table 2: Patient Characteristics $(\mathrm{N}=9)$

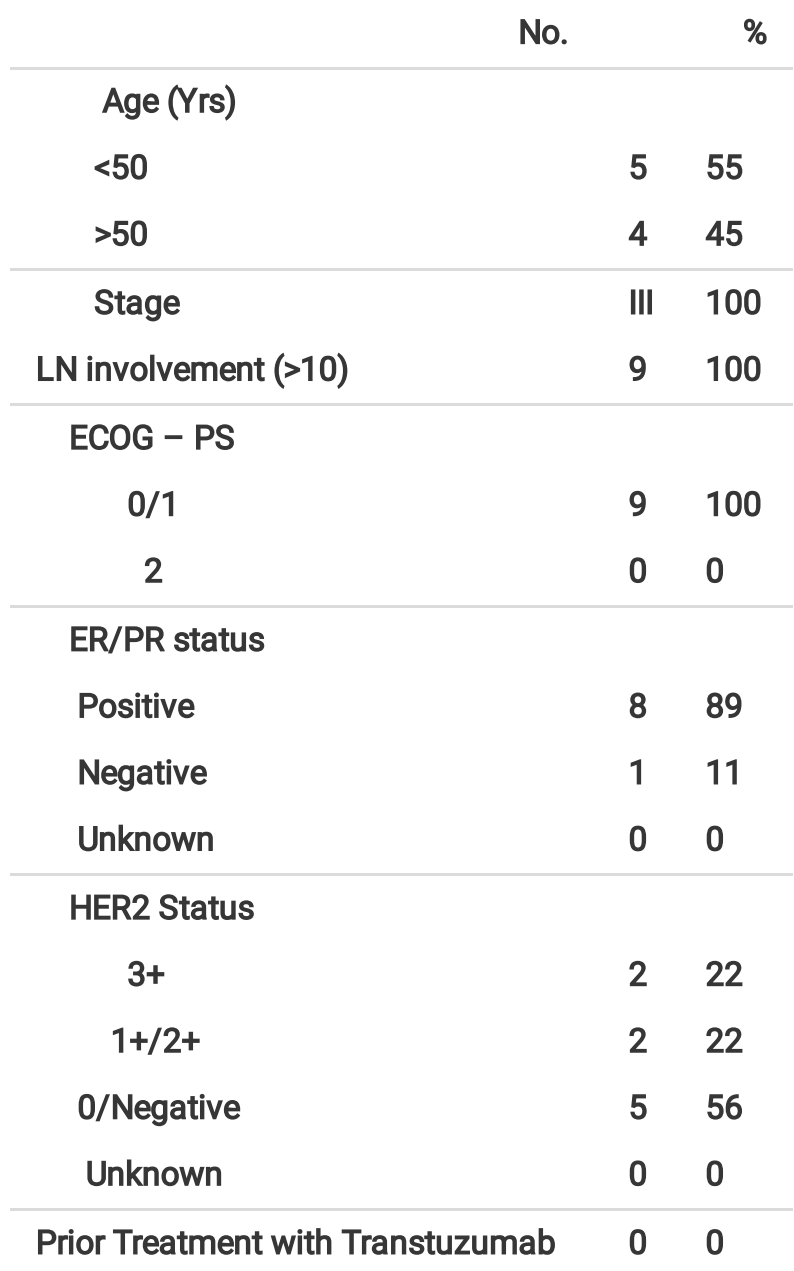


Page 12/18 
Table 3: Summary of Product Expansion, Viability, and Pre- and Post-Expansion Phenotype

\begin{tabular}{clllllllllll} 
Pt. & FG \# & $\begin{array}{l}\text { Days of } \\
\text { Culture }\end{array}$ & MNC & $\begin{array}{l}\text { \%CD3 } \\
\text { Pre }\end{array}$ & $\begin{array}{l}\text { \%CD4 } \\
\text { Pre }\end{array}$ & $\begin{array}{l}\text { \%CD8 } \\
\text { Pre }\end{array}$ & $\begin{array}{l}\text { Total } \\
\text { Harvest 10 }\end{array}$ & $\begin{array}{l}\text { Viability } \\
(\%)\end{array}$ & $\begin{array}{l}\text { \% CD3 } \\
\text { Harvest }\end{array}$ & $\begin{array}{l}\% \text { CD4 } \\
\text { Harvest }\end{array}$ & $\begin{array}{l}\% \text { CD8 } \\
\text { Harvest }\end{array}$ \\
\hline 1 & 00482 & 14 & NA & NA & NA & NA & NA & NA & NA & NA & NA \\
\hline 2 & 60031 & 13 & 15.3 & 76 & 8 & 69 & 44.3 & $88 \%$ & 92 & 19 & 76 \\
& 60051 & 11 & 6.17 & 29 & 9 & 11 & 48.3 & $95 \%$ & 91 & 69 & 22 \\
\hline 3 & 60119 & 14 & 6.56 & 59 & 32 & 27 & 54.2 & $97 \%$ & 95 & 34 & 64 \\
\hline 4 & 60114 & 10 & 18.06 & 54 & 36 & 18 & 82.4 & $87 \%$ & 94 & 70 & 26 \\
\hline 5 & 60200 & 12 & 19.3 & 55 & 42 & 14 & 153 & $98 \%$ & 82 & 35 & 52 \\
\hline 6 & 60135 & 13 & 16.9 & 57 & 33 & 24 & 88 & $92 \%$ & 94 & 19 & 88 \\
\hline 7 & 91787 & 11 & 23.5 & 41 & 21 & 20 & 117.3 & $90 \%$ & 94 & 24 & 70 \\
\hline 8 & 91801 & 14 & 18.8 & 22 & 8.5 & 9.8 & 192.1 & 91.9 & 78.4 & 38.2 & 32.0 \\
\hline 9 & 01717 & 13 & 16.8 & 13 & 8 & 5 & 160 & 94 & 89.33 & 59.59 & 38.93
\end{tabular}

Table 4: Toxic Reaction Incidence and Grade based on NCI Toxicity Criteria, v2 


\begin{tabular}{|c|c|c|c|c|c|}
\hline \multirow[t]{2}{*}{ Reaction } & \multirow{2}{*}{$\begin{array}{l}\text { \# Patients Affected } \\
\text { (\% of total) } \\
n=9\end{array}$} & \multicolumn{4}{|c|}{ Total \# of Episodes by Grade } \\
\hline & & 1 & 2 & 3 & 4 \\
\hline Nausea & $1(11.1 \%)$ & & & 1 & \\
\hline Vomiting & $1(11.1 \%)$ & & & 1 & \\
\hline Chills & $6(66.6 \%)$ & & & 6 & \\
\hline Fever & $6(66.6 \%)$ & 6 & 6 & & \\
\hline Malaise & $6(66.6 \%)$ & 4 & 2 & & \\
\hline Hypotension & $1(11.1 \%)$ & & & 1 & \\
\hline
\end{tabular}

Table 5: Cytokine Response Patterns in 5 Patients 
$\begin{array}{lllllllllllll}\text { Cytokines Patient Base Pre Pre Pre Pre Pre Pre Pre Pre } 1 \mathrm{Wk} & 1 \mathrm{MO} & 2 \mathrm{MO}\end{array}$ $\begin{array}{lllllllllllll}\text { ID } & \text { Inf } 1 & \text { Inf } 2 & \text { Inf } 3 & \text { Inf } 4 & \text { Inf } 5 & \text { Inf } 6 & \text { Inf } 7 & \text { Inf } 8 & \text { Post } & \text { Post } & \text { Post }\end{array}$

IL-2

$\begin{array}{lllllllllllll}\text { FG60114 } & 0 & 23 & 8 & 13 & 8 & 273 & \mathbf{5 9 2} & 455 & 261 & \mathbf{2 0 8} & \mathbf{2 4 7} & \mathbf{2 6 0} \\ \text { FG60119 } & 56 & 0 & 0 & 12 & 47 & 12 & 3 & & \mathbf{9} & \mathbf{1 3} & \end{array}$

IFN-g

\begin{tabular}{llllllllllllll} 
FG60031 & & 30 & 24 & 12 & 32 & 6 & & 30 & \multicolumn{3}{l}{} \\
FG60200 & 0 & 545 & 33 & 29 & 2 & $\mathbf{3 5 8 6}$ & 350 & 234 & 232 & $\mathbf{3 8}$ & & \\
FG60135 & 0 & 49 & 1 & 0 & 0 & 0 & 271 & $\mathbf{5 8 6}$ & 291 & $\mathbf{7 3}$ & $\mathbf{5 9}$ & \\
FG60114 & $\mathbf{3 2 0}$ & 145 & 87 & 64 & 37 & 13 & 93 & 121 & 78 & $\mathbf{5 4}$ & $\mathbf{5 4}$ & $\mathbf{2 7}$ \\
FG60119 & 12 & 0 & 0 & 16 & 0 & 0 & 0 & & 0 & 0 & &
\end{tabular}

GM-CSF

$\begin{array}{lllllllllllll}\text { FG60031 } & 15 & 2 & 1 & 5 & 15 & & 4 & & 2 & & \\ \text { FG60200 } & 0 & 46 & 0 & 0 & 0 & \mathbf{1 8 1} & 92 & 38 & 37 & 1 & & \\ \text { FG60135 } & 0 & \mathbf{1 5 8} & 17 & 0 & 11 & 0 & 9 & 22 & 20 & 0 & 0 & \\ \text { FG60114 } & 0 & 0 & 0 & 0 & 0 & 23 & 63 & \mathbf{8 3} & 72 & \mathbf{4 0} & \mathbf{4 3} & \mathbf{2 1} \\ \text { FG60119 } & 0 & 0 & 22 & 0 & 0 & 16 & 0 & & 0 & 0 & & \end{array}$




\begin{tabular}{llllllllllllll} 
& FG60135 & 0 & 61 & 51 & 53 & 50 & 3 & 48 & 155 & 171 & 40 & 12 & \\
\hline & FG60114 & 0 & 0 & 0 & 0 & 0 & 54 & 213 & $\mathbf{2 3 5}$ & 140 & $\mathbf{1 1 9}$ & $\mathbf{1 1 2}$ & $\mathbf{6 5}$ \\
\hline \multirow{3}{*}{ IL-13 } & FG60119 & 0 & 0 & 0 & 5 & $\mathbf{1 2 1}$ & 36 & 18 & & 9 & 9 & & \\
& FG60031 & 2 & 2 & 2 & 25 & & & 20 & & 3 & & \\
& FG60200 & 0 & 2 & 1 & 3 & 2 & $\mathbf{4 5 4}$ & 233 & 151 & $\mathbf{1 5 6}$ & $\mathbf{3 7}$ & & $\mathbf{2 1}$
\end{tabular}

Bold = peak/persistence

\section{Figures}

Figure 1.
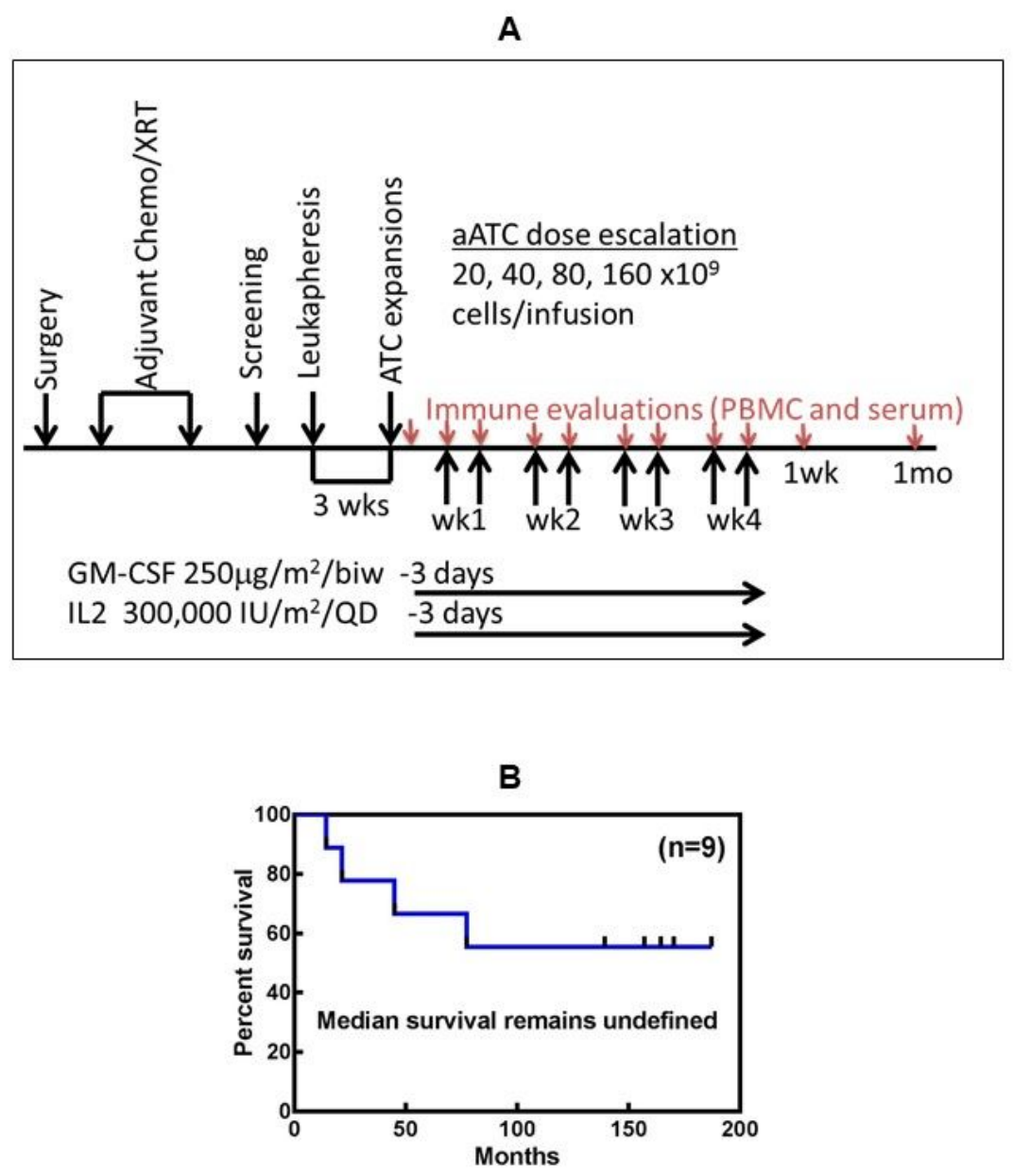

Figure 1 
Treatment schema shows leukapheresis to obtain T cells for expansion. HER2Bi armed ATC (BATs) were administered twice weekly for four consecutive weeks. All patients received SQ IL-2 (300,000 IU/m2/day) and GM-CSF ( $250 \mu \mathrm{g} / \mathrm{m} 2 /$ twice weekly) beginning 3 days before the first BATs infusion and ending 1 week after the last BATs infusion. Immune testing was performed at indicated time points after BATs infusions. 1B. K-M curve for all 9 patients (2 HER2 $3+$ and 7 HER2 0-2+ patients).

Figure 2.
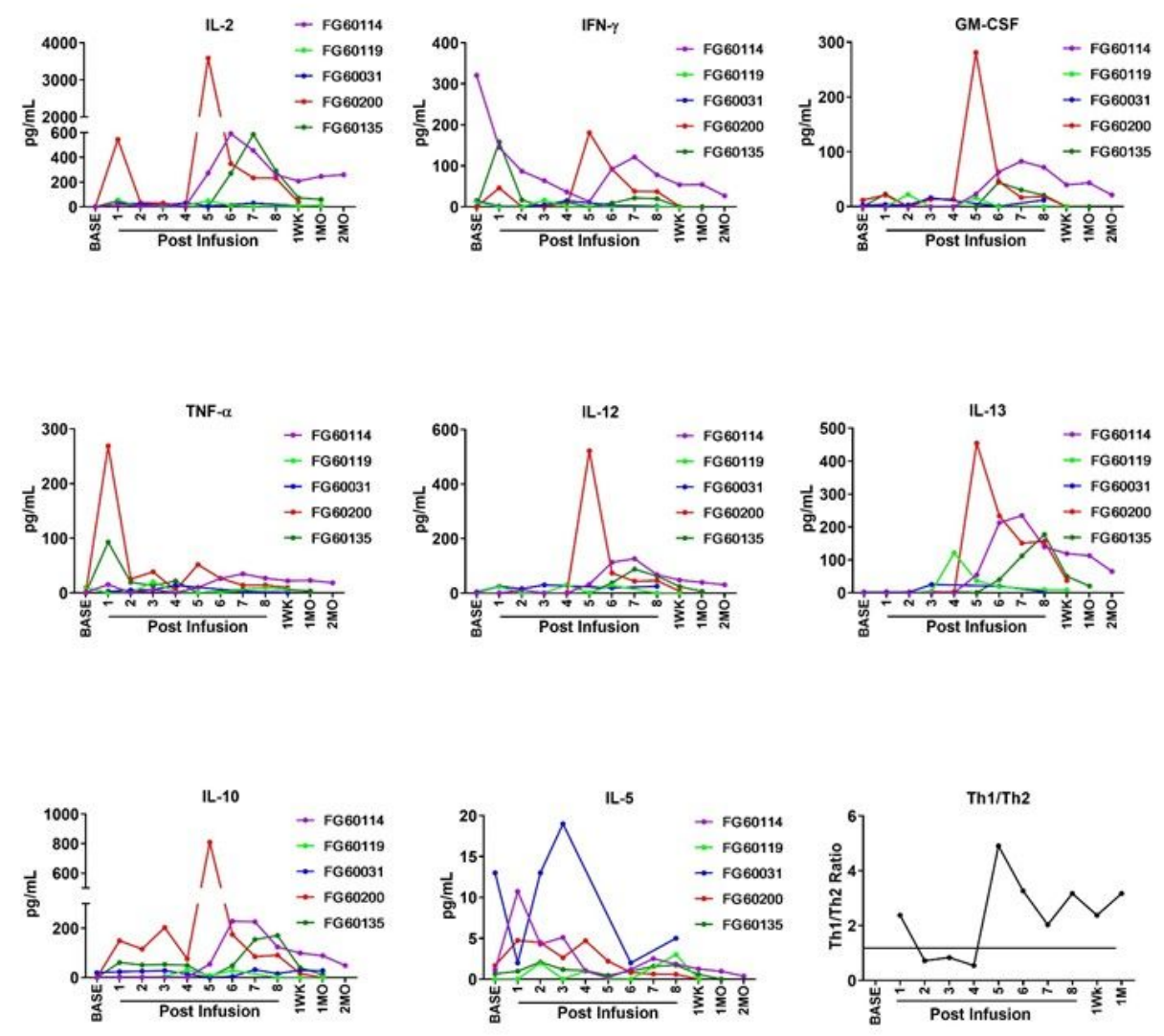

\section{Figure 2}

Shows profile of serum cytokines. Analysis of serum samples $(n=5)$ at pre-immunotherapy (BASE), after every BATs infusion (1-8 infusions), and post IT (1 week and 1 month after completion of IT). Armed ATC infusions (IT) show increases in IFN-区, IL-2, IL-12,

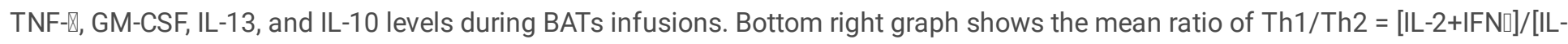
4+IL-10] at indicated time points. 
Figure 3.

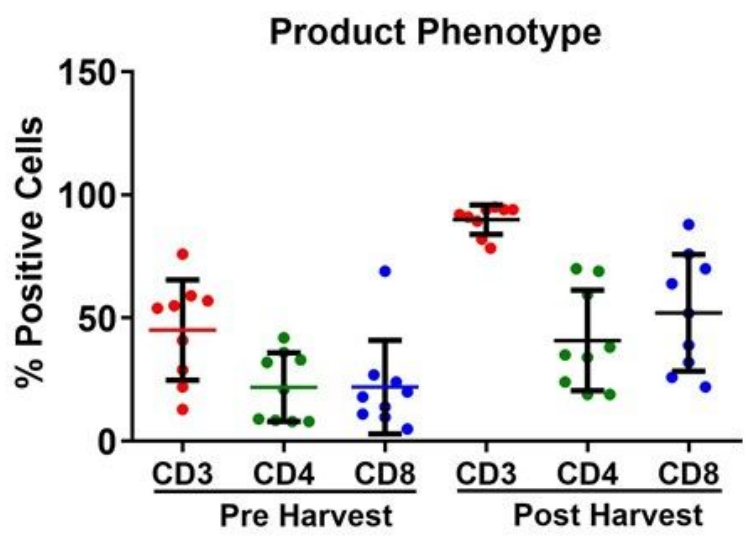

Figure 3

Shows the proportion of CD3, CD4, and CD8 T cells in apheresis product (pre-harvest) and the proportion of CD3, CD4, and CD8 T cells after 14 days of expansion. 